Balıkesir Üniversitesi Tıp Fakültesi, Çocuk Sağlığı ve Hastalıkları Anabilim Dalı, Çocuk Nöroloji, Balıkesir e-posta:

drhilalaydin@gmail.com ORCID: 0000-0002-2448-1270

${ }^{2}$ Adıyaman Üniversitesi Tıp Fakültesi, Çocuk Sağlığı ve Hastalıkları Anabilim Dalı,

Adıyaman e-posta:

drhbucak@gmail.com ORCID: 0000-0002-3074-6327

Atıf iç̧in: Hilal AYDIN, Yeni Kurulan Bir Çocuk Nöroloji Polikliniğine Başvuran Illk 1000

Hastanın Retrospektif

Değerlendirilmesi, Balıkesir Medical Journal, 2021;5(1):54-59

Başvuru Tarihi: 02.02.2021 Kabul Tarihi: 26.02.2021 Yayınlanma Tarihi: 28.02.2021

Sorumlu Yazar:

Hilal AYDIN,

Balıkesir Üniversitesi Tıp Fakültesi, Çocuk Sağlığı ve Hastalıkları Anabilim Dalı, Çocuk Nöroloji, Balıkesir e-posta:

drhilalaydin@gmail.com

\section{Yeni Kurulan Bir Çocuk Nöroloji Polikliniğine Başvuran Illk 1000 Hastanın Retrospektif Değerlendirilmesi}

\section{A Retrospective Analysis of the First 1,000 Patients Being Admitted to A Newly Established Pediatric Neurology Outpatient Clinic}

\author{
Hilal AYDIN ${ }^{1}$, ibrahim Hakan BUCAK ${ }^{2}$
}

öz

Amaç: Nörolojik hastalık profili yetişkinler ve çocuklar arasında farklılık göstermekle birlikte demografik veri ve tanı dağıımları ile ilgili kısıtlı sayıda çalışma bulunmaktadır. Bu çalışmada yeni kurulan çocuk nöroloji polikliniğine başvuran ilk 1000 hastanın geriye yönelik değerlendirilmesi amaçlandı.

Gereç ve Yöntemler: Üçüncü basamak bir üniversite hastanesinde yeni kurulan çocuk nöroloji polikliniğine başvuran ilk 1000 hastaya ait dosyalar retrospektif değerlendirildi. Hasta dosyalarından yaş, cinsiyet, tanı, uyruk ve sosyal güvence bilgileri elde edildi.

Bulgular: Çalışmaya alınan hastaların 561'i $(\% 56,1)$ erkek, 439'ü $(\% 43,9)$ kız idi. Erkek hastaların yaş ortalaması $64 \pm 61$ ay (1216 ay), kız hastaların yaş ortalaması 105,76 $\pm 56,6$ ay (1-216 ay) idi. Olgu sayısının en fazla olduğu yaş grubu 0-2 yaş ( $\mathrm{n}=328$, $\% 32,8)$, en az olduğu yaş grubu 16-18 yaş ( $n=77, \% 7,7)$ idi. Olguların 60'ı (\%6) Suriye uyruklu iken, 940'ı '(\%94) Türkiye Cumhuriyeti (TC) uyruklu idi. Olguların $848(\% 84,8)^{\prime}$ i genel sağlık sigortası kapsamında idi. Tanı grupları incelendiğinde ilk üç sırada $254(\% 25,4)$ olgu ile epilepsi, $240(\% 24)$ olgu ile sağılıklı çocuk muayenesi ve $139(\% 13,9)$ olgu ile baş ağrısı gelmekte idi.

Sonuç: Çalışmada elde ettiğimiz veriler yeni kurulan üçüncü basamak bir çocuk nöroloji polikliniğine ait hasta profilini detaylandıran ve değerlendiren ilk çalışmadır. Bu çalışma sonucunda hasta profilinin önceden tahmin edilebilmesi ile yeni kurulacak merkezlerin öncelikleri tahmin edilebilecektir. Konu ile ilgili daha fazla sayıda çalışmaya ihtiyaç bulunmaktadır.

Anahtar Kelimeler: Çocuk nöroloji; cinsiyet; poliklinik; tanı; yaş

\section{ABSTRACT}

Aim: The neurological disease profile is different in adult and pediatric patients. There are a limited number of studies on demographic and diagnostic data distributions. This study aimed to retrospectively analyze the first 1,000 patients being admitted to a newly established pediatric neurology outpatient clinic.

Materials and Methods: This study retrospectively analyzed the files of the first 1,000 patients who were admitted to a newly established pediatric neurology outpatient clinic of a tertiary university hospital. Age, gender, diagnosis, nationality, and social security information of the patients were recorded.

Results: Five hundred sixty-one of the patients $(56.1 \%)$ were male and $439(43.9 \%)$ were female, with a mean age of $64 \pm 61$ (1-216) months and 105.76 \pm 56.6 (1-216) months, respectively. The age groups with the highest and lowest number of cases were the $0-2$ years age group $(n=328,32.8 \%)$ and the $16-18$ years age group $(n=77,7.7 \%)$, respectively. Sixty of the patients (6\%) were Syrian whereas $940(94 \%)$ were Turkish. Only 848 patients $(84.8 \%)$ had general health insurance. As for the diagnoses, epilepsy was observed to rank in first place $(n=254,25.4 \%)$, followed by healthy child examinations $(n=240$, $24 \%)$, and headache ( $n=139,13.9 \%)$.

Conclusion: To the best of our knowledge, this is the first study investigating and evaluating the patient profile of a newly established tertiary pediatric neurology outpatient clinic in detail. Although it may help predict the priorities of centers to be opened in the future, since it enables the patient profile to be predicted in advance, there is still a need for further studies on this subject.

Keywords: Child neurology; diagnosis; gender; outpatient clinic; age 
Tıp alanında gelişmeler, yan dal eğitim programları, ülkemizin her köşesinde üçüncü basamak hastanelerin hizmet vermeye başlaması ile çocuk nörolojisi kliniklerinin kurulması yaygın duruma gelmiştir. Çocuk nörolojisi ilgi alanı dahilinde; beyin, omurilik, sinir ve kas hastalıklarıyla ilgilenen bir tıp uzmanlık yan dalıdır. Çocuk nörolojinin kendi içerisinde de çok geniş ve çeşitli tanı yelpazesi (epilepsi, senkop, vertigo, demyelinizan hastalıklar, stroke, kas-sinir hastalıkları gibi) bulunmaktadır. Nörolojik hastalık profilinin karakteristik olarak yetişkinler ve çocuklar arasında farklılık gösterdiği ve her yaş grubu için bağımsız bir araştırma gerektirdiği kabul edilmektedir (1). Bununla birlikte pediatrik nörolojik hastalıklar için yayınlanmış epidemiyolojik morbidite verileri yetişkinlere göre daha sınırlı sayıdadır. 106 ülkeyi içeren (dünya nüfusunun \%90'ını kapsayan) bir çalışmada, ülkeler ekonomik gruplar halinde değerlendirilmiş ve ekonomik olarak aynı grupta bulunanlarda nörolojik hastalıkların sıklığının benzerlik gösterdiği belirlenmiştir (2). Ofovme 2005 yılında yayınladıkları bildiride; pediatrik nörolojik hastalık tanıları incelendiğinde beş yaş ve altı çocuklarda en sık karşılaşılan hastalıklar; febril konvülziyon (\%35,1), serebral sıtma (\%28) ve menenjit (\%27) olduğunu saptamışlardır (3). Literaturde erişkin ve çocuklarda görülen nörolojik hastalıkların tanı dağılımı ile ilgili kısıtlı sayıda çalışma bulunmaktadır (4).

Bu çalışmada yeni kurulan bir çocuk nöroloji polikliniğine başvuran ilk 1000 hastanın retrospektif olarak değerlendirilmesi amaçlandı.

\section{GEREÇ VE YÖNTEMLER}

Üçüncü basamak üniversite hastanesi çocuk nöroloji polikliniğine Ekim 2017-Aralık 2017 tarihleri arasında başvuran ilk 1000 hastanın dosyaları retrospektif değerlendirildi. Hastaların yaş (ay), cinsiyet (kız, erkek), uyruk (Türkiye Cumhuriyeti, Suriye gibi), sosyal güvenceleri [Genel sağlık sigortası (GSS), özel sigorta gibi] ve tanıları kaydedildi. Çalışmaya dahil edilen hastalar yaş gruplarına göre; 0-2 yaş, 3-5 yaş, 6-8 yaş, 9-12 yaş, 13-15 yaş, 16-18 yaş olarak ayrıldı. Çalışma için Adıyaman Üniversitesi Girişimsel Olmayan Klinik Araştırmalar Etik Kurulu'ndan onay alınmıştır (İzin no: 2020/8-18).

\section{İstatiksel Analiz}

Verilerin istatistiksel olarak değerlendirilmesi SPSS (Statistical Package for Social Sciences, ABD) paket programı ile yapıldı. Tanımlayıcı istatistikler ortalama, standart sapma, ortanca (minimum-maksimum), frekans dağılımı ve yüzde olarak sunuldu.

\section{BULGULAR}

Çocuk Nöroloji polikliniğine başvuran ilk 1000 hastanın 561'ı (\%56,1) erkek; 439’u (\%43,9) kız idi. Erkek hastaların yaş ortalaması $64 \pm 61$ ay (1-216 ay), kız hastaların yaş ortalaması $105,76 \pm 56,6$ ay (1-216 ay) idi. Olgu sayısının en fazla olduğu yaş grubu 0-2 yaş ( $n=328, \% 32,8)$, ikinci sıklıkla 9-12 yaş (n=193, \%19,3), üçüncü sıklıkla 3-5 yaş ( $n=168, \% 16,8)$, olgu sayısının en az olduğu yaş grubu $16-18$ yaş $(n=77, \% 7,7)$ idi. Erkeklerde olgu sayısının en fazla olduğu yaş grubu 0-2 yaş ( $n=261, \% 26,1)$, en az olgu olduğu yaş grubu 16-18 yaş iken ( $n=29$, 
\%2,9), kızlarda olgu sayısının en fazla olduğu yaş grubu 9-12 yaş ( $n=120, \% 12)$, en az olgu olduğu yaş grubu 1618 yaş $(n=77, \% 7,7)$ idi (Tablo1).

Cinsiyet

\begin{tabular}{llll}
\hline Yaş aralığı & Kız n $(\%)$ & Erkek n $(\%)$ & n $(\%)$ \\
\hline $\mathbf{0 - 2}$ yaş & $67(\% 6,7)$ & $261(\% 26,1)$ & $328(\% 32,8)$ \\
3-5 yaş & $69(\% 6,9)$ & $99(\% 9,9)$ & $168(\% 16,8)$ \\
6-8 yaş & $79(\% 7,9)$ & $62(\% 6,2)$ & $141(\% 14,1)$ \\
9-12 yaş & $120(\% 12)$ & $73(\% 7,3)$ & $193(\% 19,3)$ \\
$\mathbf{1 3 - 1 5}$ yaş & $56(\% 5,6)$ & $37(\% 3,7)$ & $93(\% 9,3)$ \\
$\mathbf{1 6 - 1 8}$ yaş & $48(\% 4,8)$ & $29(\% 2,9)$ & $77(\% 7,7)$ \\
\hline \multicolumn{4}{c}{}
\end{tabular}

Altmış (\%6) hasta Suriye uyruklu iken, 940 (\%94) hasta Türkiye Cumhuriyeti (TC) uyruklu idi. Altmış (\%6) hasta Suriyeli misafirler, $92(\% 9,2)$ hasta özel sağlık sigorta, $848(\% 84,8)$ hasta GSS kapsamında olduğu belirlendi (Tablo 2).

\begin{tabular}{|c|c|c|c|c|}
\hline Yaş aralığı & $\begin{array}{l}\text { Özel Sağlık } \\
\text { Sigortası } \\
\text { n (\%) }\end{array}$ & $\begin{array}{l}\text { Genel Sağlık } \\
\text { Sigortası } \\
\text { n }(\%)\end{array}$ & $\begin{array}{l}\text { Suriyeli } \\
\text { Misafirler } \\
\text { n (\%) }\end{array}$ & n $(\%)$ \\
\hline 0-2 yaş & $29(\% 2,9)$ & $288(\% 28,8)$ & $11(\% 1,1)$ & $328(\% 32,8)$ \\
\hline 3-5 yaş & $17(\% 1,79)$ & $145(\% 14,5)$ & $6(\% 0,6)$ & $168(\% 16,8)$ \\
\hline 6-8 yaş & $15(\% 1,59)$ & $115(\% 11,5)$ & $11(\% 1,1)$ & $141(\% 14,1)$ \\
\hline 9-12 yaş & $20(\% 2)$ & $155(\% 15,5)$ & $18(\% 1,8)$ & $193(\% 19,3)$ \\
\hline $13-15$ yaş & $5(\% 0,56)$ & $80(\% 8)$ & $8(\% 0,8)$ & $93(\% 9,3)$ \\
\hline 16-18 yaş & $6(\% 0,6)$ & $65(\% 6,5)$ & $6(\% 0,6)$ & $77(\% 7,7)$ \\
\hline
\end{tabular}

Hastalara ait tanılar incelendiği; $254(\% 25,4)$ olgu epilepsi, 240 (\%24) olgu sağlıklı çocuk muayanesi ve $139(\% 13,9)$ olgu baş ağrısı olarak sisteme kaydedildiği görüldü (Tablo 3).

\begin{tabular}{|c|c|c|c|c|c|c|c|}
\hline Tanılar & $\begin{array}{c}\text { 0-2 yaș } \\
\text { n (\%) }\end{array}$ & $\begin{array}{c}\text { 3-5 yaș } \\
\text { n (\%) }\end{array}$ & $\begin{array}{l}\text { 6-8 yaș } \\
\text { n (\%) }\end{array}$ & $\begin{array}{c}9-12 \text { yaș } \mathbf{n} \\
(\%)\end{array}$ & $\begin{array}{c}\text { 13-15yaș } \\
\text { n (\%) }\end{array}$ & $\begin{array}{c}\text { 16-18 yaș } \\
\text { n (\%) }\end{array}$ & $\begin{array}{l}\text { Total } \\
\text { n (\%) }\end{array}$ \\
\hline Febril Konvulziyon & $31(\% 3,1)$ & $14(\% 1,4)$ & 0 & 0 & 0 & 0 & $45(\% 4,5)$ \\
\hline Tortikollis & $2(\% 0,2)$ & 0 & $1(\% 0,1)$ & 0 & 0 & 0 & $3(\% 0,3)$ \\
\hline Epilepsi & $53(\% 5,3)$ & $53(\% 5,3)$ & $53(\% 5,3)$ & $52(\% 5,2)$ & $19(\% 1,9)$ & $24(\% 2,4)$ & $254(\% 25,4)$ \\
\hline Konjenital Hipotoni & $10(\% 1)$ & 0 & 0 & 0 & 0 & 0 & $10(\% 1)$ \\
\hline Makrosefali & $3(\% 0,3)$ & 0 & 0 & 0 & 0 & 0 & $3(\% 0,3)$ \\
\hline Nöromotor Gelișimsel Gerilik & $26(\% 2,6)$ & $19(\% 1,9)$ & $5(\% 0,5)$ & $11(\% 1,1)$ & $3(\% 0,3)$ & 0 & $64(\% 6,4)$ \\
\hline Nörofibromatozis Tip 1 & $1(\% 0,1)$ & $1(\% 0,1)$ & $1(\% 0,1)$ & 0 & 0 & $1(\% 0,1)$ & $4(\% 0,4)$ \\
\hline Hidrosefali & $10(\% 1)$ & $5(\% 0,5)$ & $1(\% 0,1)$ & $1(\% 0,1)$ & 0 & 0 & $17(\% 1,7)$ \\
\hline Sağlıklı Çocuk Muayanesi & $\begin{array}{c}142 \\
(\% 14,2)\end{array}$ & $31(\% 3,1)$ & $21(\% 2,1)$ & $18(\% 1,8)$ & $18(\% 1,8)$ & $10(\% 1)$ & $240(\% 24)$ \\
\hline Myoklonus & $3(\% 0,3)$ & 0 & 0 & 0 & 0 & $1(\% 0,1)$ & $4(\% 0,4)$ \\
\hline Görme Bozukluğu & 0 & $2(\% 0,2)$ & $2(\% 0,2)$ & $3(\% 0,3)$ & 0 & 0 & $7(\% 0,7)$ \\
\hline
\end{tabular}




\begin{tabular}{|c|c|c|c|c|c|c|c|}
\hline Monopleji & $1(\% 0,1)$ & 0 & 0 & 0 & 0 & 0 & $1(\% 0,1)$ \\
\hline Senkop & $6(\% 0,6)$ & $3(\% 0,3)$ & $9(\% 0,9)$ & $8(\% 0,8)$ & $4(\% 0,4)$ & $6(\% 0,6)$ & $36(\% 3,6)$ \\
\hline Otizm & $2(\% 0,2)$ & $2(\% 0,2)$ & $5(\% 0,5)$ & $1(\% 0,1)$ & 0 & $1(\% 0,1)$ & $11(\% 1,1)$ \\
\hline Zihinsel Yetersizlik & 0 & $1(\% 0.1)$ & $4(\% 0,4)$ & $6(\% 0,6)$ & $3(\% 0,3)$ & $1(\% 0,1)$ & $15(\% 1,5)$ \\
\hline Konușma Bozukluğu & $10(\% 1)$ & $9(\% 0,9)$ & $5(\% 0,5)$ & $4(\% 0,4)$ & 0 & $1(\% 0,1)$ & $29(\% 2,9)$ \\
\hline Mikrosefali & $6(\% 0,6)$ & $3(\% 0,3)$ & 0 & 0 & 0 & 0 & $9(\% 0,9)$ \\
\hline Tremor & $1(\% 0,1)$ & 0 & 0 & $2(\% 0,2)$ & 0 & $2(\% 0,2)$ & $5(\% 0,5)$ \\
\hline Tuberoskleroz & $1(\% 0,1)$ & 0 & $1(\% 0,1)$ & 0 & 0 & 0 & $2(\% 0,2)$ \\
\hline \multirow[t]{2}{*}{ Baș ağrısı } & 0 & $14(\% 1,4)$ & $18(\% 1,8)$ & $59(\% 5,9)$ & $32(\% 3,2)$ & 16 & 139 \\
\hline & & & & & & $(\% 1,6)$ & $(\% 13,9)$ \\
\hline Serebral Palsi & $4(\% 0,4)$ & $4(\% 0,4)$ & $6(\% 0,6)$ & $7(\% 0,7)$ & $2(\% 0,2)$ & $3(\% 0,3)$ & $26(\% 2,6)$ \\
\hline Baș dönmesi & 0 & $1(\% 0,1)$ & $2(\% 0,2)$ & $9(\% 0,9)$ & $8(\% 0,8)$ & $7(\% 0,7)$ & $27(\% 2,7)$ \\
\hline Down Sendromu & $8(\% 0,8)$ & $3(\% 0,3)$ & $1(\% 0,1)$ & 0 & 0 & 0 & $12(\% 1,2)$ \\
\hline Nistagmus & $2(\% 0,2)$ & $1(\% 0,1)$ & $2(\% 0,2)$ & $1(\% 0,1)$ & 0 & 0 & $6(\% 0,6)$ \\
\hline Uyku bozukluğu & 0 & 0 & 0 & $3(\% 0,3)$ & $1(\% 0,1)$ & 0 & $4(\% 0,4)$ \\
\hline Mikroftalmi & $1(\% 0,1)$ & 0 & 0 & 0 & 0 & 0 & $1(\% 0,1)$ \\
\hline Migren & 0 & 0 & 0 & $1(\% 0,1)$ & $1(\% 0,1)$ & $2(\% 0,2)$ & $4(\% 0,4)$ \\
\hline *DEHAB & 0 & 0 & $1(\% 0,1)$ & 0 & 0 & 0 & $1(\% 0,1)$ \\
\hline Kraniosinostozis & $1(\% 0,1)$ & 0 & 0 & 0 & 0 & 0 & $1(\% 0,1)$ \\
\hline Üriner inkontinans & 0 & $1(\% 0,1)$ & $1(\% 0,1)$ & $3(\% 0,3)$ & $2(\% 0,2)$ & $1(\% 0,1)$ & $8(\% 0,8)$ \\
\hline Myastenia Gravis & 0 & 0 & 0 & 0 & 0 & $1(\% 0,1)$ & $1(\% 0,1)$ \\
\hline Fasiyal asimetri & 0 & 0 & $1(\% 0,1)$ & $3(\% 0,3)$ & 0 & 0 & $4(\% 0,4)$ \\
\hline Strabismus & $3(\% 0,3)$ & 0 & 0 & 0 & 0 & 0 & $3(\% 0,3)$ \\
\hline Brachial Pleksopati & $1(\% 0,1)$ & 0 & 0 & 0 & 0 & 0 & $1(\% 0,1)$ \\
\hline Tik & 0 & 0 & 0 & $1(\% 0,1)$ & 0 & 0 & $1(\% 0,1)$ \\
\hline Rett Sendromu & 0 & $1(\% 0,1)$ & $1(\% 0,1)$ & 0 & 0 & 0 & $2(\% 0,2)$ \\
\hline $\begin{array}{l}\text { Total n } \\
\end{array}$ & $\begin{array}{c}328 \\
(\% 32,8)\end{array}$ & $\begin{array}{c}168 \\
(\% 16,8)\end{array}$ & $\begin{array}{c}141 \\
(\% 14,1)\end{array}$ & $\begin{array}{c}193 \\
(\% 19,3)\end{array}$ & $\begin{array}{c}93 \\
(\% 9,3)\end{array}$ & $\begin{array}{c}77 \\
(\% 7,7)\end{array}$ & $\begin{array}{c}1000 \\
(\% 100)\end{array}$ \\
\hline
\end{tabular}

Tablo 3. Yaș gruplarına göre tanıların dağılımı (DEHAB; Dikkat eksikliği ve hiperaktivite bozukluğu)

\section{TARTIŞMA}

Nörolojik bozukluklar pediatrik yaş grubunda morbidite ve mortalitenin başlıca nedenidir ve hastaların yaşam kalitesini olumsuz etkilemektedir (5). Yeni kurulan üçüncü basamak bir hastanenin çocuk nöroloji hastalarının demografik verileri ve tanı dağılımlarının bilinmesi benzer kurulacak kliniklere yol gösterici olmasının yanında hastalara daha iyi hizmet verilmesi için ilk adım olacaktır. Çocuklarda görülen başlıca nörolojik bozukluklar arasında epilepsi, baş ağrısı, migren, serebral palsi, dikkat eksikliği ve hiperaktivite bozukluğu, otizm ve yaygın gelişimsel bozukluklar, gelişimsel gerilik, nonparoksizmal bozukluklar, demiyelinizan hastalıklar, nöromuskuler hastalıklar ve nörodejeneratif hastalıklar bulunmaktadır Epilepsi, pediatrik yaş grubunda en sık rastlanılan nörolojik hastalıktır (6). Ogbe ve arkadaşları en yaygın nörolojik hastalıkların epilepsi 
$(\% 25,9)$, serebral palsi $(\% 19,3)$, postfebril nörolojik hastalıklar $(\% 12,5)$, konuşma ve dil problemleri $(\% 10,9)$, Down Sendromunu da içeren zihinsel gerilik $(\% 10,7)$ olduğunu bildirmişlerdir (7). Moges ve arkadaşlarının yayınladıkları çalışmada en sık görülen nörolojik hastalıklar; epilepsi (\%24,6), serebral palsi $(\% 15,4)$, SSS enfeksiyonları $(\% 9,5)$, mikrosefali $(\% 7,6)$ ve mental gerilik $(\% 7,2)$ idi (8). 2007'de Wammanda ve arkadaşları pediatrik nöroloji kliniğine en sık üç başvuru nedenin gelişimsel gerilik, konvülziyon ve yürüyüş bozukluğu olduğunu belirtmişlerdir (9). Izuora ve arkadaşları 1991 yılında sırasıyla en sık görülen beş hastalığı epilepsi ve febril nöbetler $(\% 28,9)$, serebral palsi $(\% 18,9)$, mental retardasyon $(\% 16,7)$, enfeksiyonlar $(\% 9,4)$ ve travma $(\% 8,9)$ olarak dökümente etmişlerdi (). Çalışmamızda olguların en sık epilepsi $(\% 25,4)$ tanısı aldığı görüldü. Bu sonuç literatür ile uyumlu idi.

Tanı dağılımı ile ilgili yapılan çalışmalarda erkek hastalarda nörolojik hastalıkların daha fazla görüldüğünü saptanmıştır (11-13). Bizim çalışmamızda literature benzer olarak ilk 1000 hastada erkek olguların daha fazla olduğu tespit edildi.

Çocuk nöroloji polikliniklerinde takip etmeye alışkın olduğumuz; stroke, demyelinizan hastalıklar, nöromuskuler hastalıklar ve nörometabolik hastalıklar gibi tanılara rastlanılmadı. Çalışmamızın retrospektif olması ve ilk 1000 hastayı çalışmaya dahil etmemizin tanı dağılımı konusunda kısıtlılıklara yol açtığını düşünmekteyiz. Ayrıca bu hastalıkların tanı dağılımımızda yer almamasını yeni kurulan merkezlerin ilk kuruldukları süreçte başka merkezde takipli olan hastaların bilgilendirilmesi ile aşılabileceğini öngörmekteyiz. İl dışında bulunan merkezlerde takip edilen olgular ilk aşamada çocuk nöroloji polikliniğe yönlendirilmesi ile epilepsi tanısı daha önce var olan, hastalar ve yeni tanı konulan olgular ilk sırayı almıştır. Kliniğin ilk kurulması ve ardından belirli bir süre geçmesi durumunda tanı dağılımlarının değişebileceği de unutulmamalıdır.

\section{SONUÇ}

Yeni kurulan üçüncü basamak bir çocuk nöroloji polikliniğinde ilk 1000 hastanın; en sık 0-2 yaş grubunda olduğu ve en sık epilepsi, baş ağrısı ve sağlıklı çocuk muayenesi tanıları ile takip edildiği belirlendi. Çalışmada elde edilen verilerin ilk kez kurulacak çocuk nöroloji kliniklerine yol gösterici olacağı sonucuna varıldı.

\section{TEŞEKKÜR}

Çocuk nöroloji kliniğinin kurulmasında önderlik eden Sayın Prof. Dr. Mehmet Turgut Hocamıza en içten dileklerimizle teşekkürlerimizi sunarız.

\section{KAYNAKLAR}

1. Tan K, Patel S, Gandhi N, Chow F, Rumbaugh J, Nath A. Burden of neuroinfectious diseases on the neurology service in a tertiary care center. Neurology. 2008;71:1160-6.

2. WHO. Neurology atlas: country resources for neurological disorders. Report of program for neurological diseases and neuroscience. 2004

3. Ofovwe GE, Ibadin OM, Okunola OP, Ofoegbu B. Pattern of emergency neurologic morbidities in children. Journal of the national medical association. 2005;97(4):488-92. 
4. Capildeo R, Haberman S, Rose FC. Neuroepidemiology in the developing countries. Journal of the Royal Society of Medicine. 1982;75:305-6.

5. Raina SK, Razdan S, Nanda R. Prevalence of neurological disorders in children less than 10 years of age in RS Pura town of Jammu and Kashmir. J Pediatr Neurosci. 2011;6:103-5.

6. Kliegman RM, Behrman RE, Jenson HB, Stanton BF. 18th ed. Chs 28, 29, 593, and 595. I and II. Philadelphia: WB Saunders; 2007. Nelson Text Book of Pediatrics; pp. 131-7. 2457, 2477-81.

7. Ogbe Z, Nyarang'o P, Mufunda P. Pattern of neurological diseases as seen in outpatient children: the experiences from Orotta Referral Hospital Asmara, Eritrea. Journal of Eritrean Medical Association. $2006 ; 1 ; 11-15$.

8. Moges A, Gizae S, Zenebe G, Kotagal S. Pattern of Neurological Disorders at Pediatric Outpatient Neurologic Services at Tikur Anbessa Specialized Hospital. Ethiop J Pediatr Child Health. 2017;14:2.

9. Wammanda RD, Onalo R, Adama SJ. Pattern of neurological disorder presenting at a paediatric neurology clinic in Nigeria. Ann Afr Med. 2007;6:73-5.

10. Izuora GI, Anis AS. Neurological Disorders in Saudi Children at the Al-Majardah General Hospital, Asir Region. 1992;12(2):191-195.

11. Oduori ML, Shah SK. The pattern of neurological diseases in African children in Kenya. East Afr Med J. 1973;50:253-260.

12. Sykes RM. Epilepsy in children in Benin City, Nigeria. Ann Trop Paediatr. 2002;22:287-296.

13. Burton KJ, Allen S. A review of neurological disorders presenting at a paediatric neurology clinic and response to anticonvulsant. Ann Trop Paediatr. 2003;23:139-143. 